San Jose State University

SJSU ScholarWorks

$5-1-2009$

\title{
The Use of the "Get Up and Go Test" as the Initial Screening Measure for Fall Risk With Community Dwelling Seniors
}

Margaret E. Hermoso

San Jose State University

Follow this and additional works at: https://scholarworks.sjsu.edu/etd_projects

Part of the Geriatric Nursing Commons

\section{Recommended Citation}

Hermoso, Margaret E., "The Use of the "Get Up and Go Test" as the Initial Screening Measure for Fall Risk With Community Dwelling Seniors" (2009). Master's Projects. 767.

DOI: https://doi.org/10.31979/etd.ewrf-eb4r

https://scholarworks.sjsu.edu/etd_projects/767

This Master's Project is brought to you for free and open access by the Master's Theses and Graduate Research at SJSU ScholarWorks. It has been accepted for inclusion in Master's Projects by an authorized administrator of SJSU ScholarWorks. For more information, please contact scholarworks@sjsu.edu. 


\section{SAN JOSE STATE UNIVERSITY SCHOOL OF NURSING}

\section{MASTER'S PROGRAM PROJECT OPTION (PLAN B) PROJECT SIGNATURE FORM}

\section{STUDENT NAME}

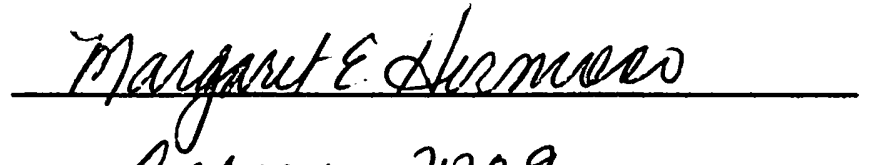

SEMESTER ENROLLED

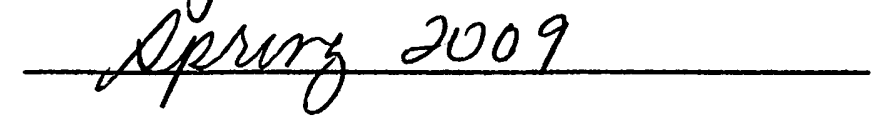

\section{TITLE OF PROJECT}

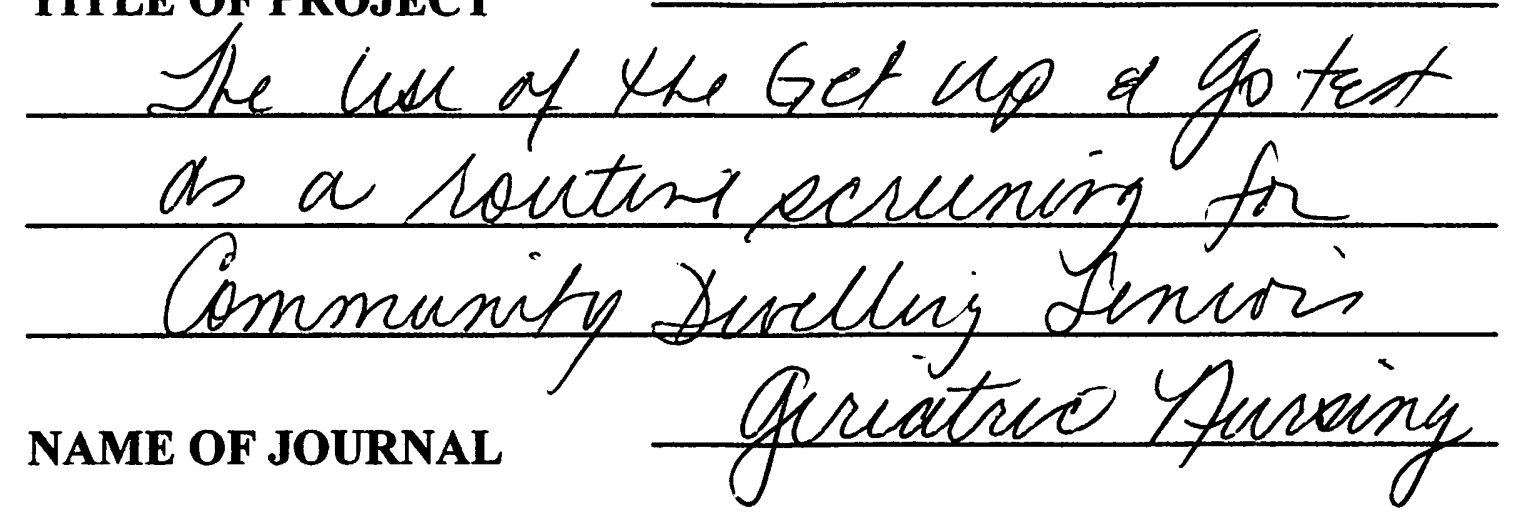

The project and the manuscript have been successfully completed and meet the standards of the School of Nursing University. The project demonstrates the application of professional knowledge, clinical expertise, and scholarly thinking. An abstract of the project and two copies of the manuscript are attached.

Dian orethe

ADVISOR'S SIGNATURE

Kanexathare

ADVISOR'S SIGNATURE

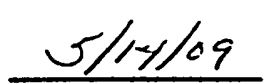

DATE

$5-20-09$

DATE

Please submit the form to the Graduate Coordinator. Attach abstract, two copies of the manuscript, and the documentation of submission to the journal (i.e., postal receipt). 
The Use of the "Get Up and Go Test" as the Initial Screening Measure for Fall Risk With Community Dwelling Seniors

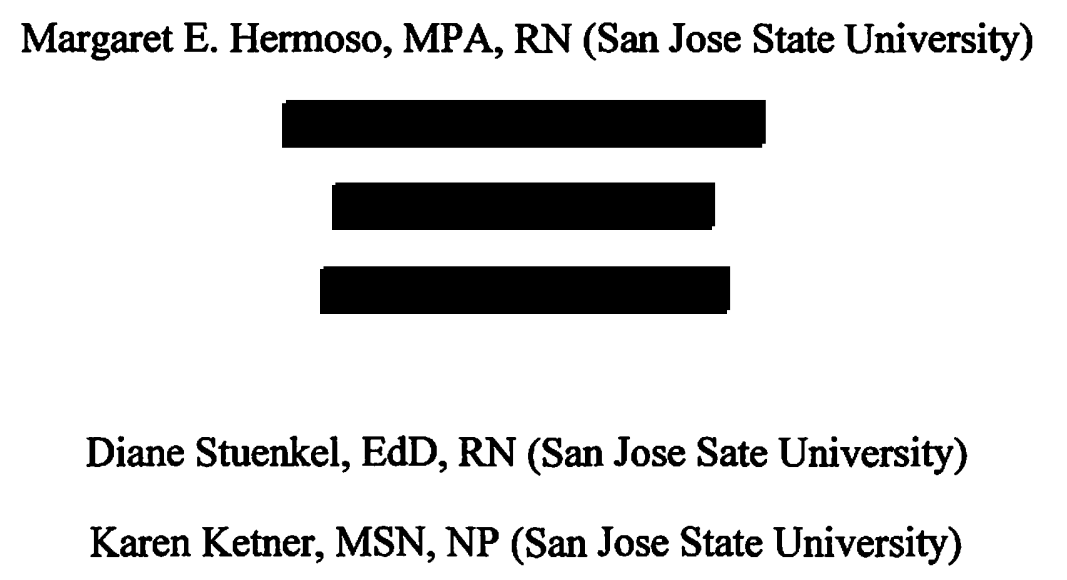

The authors have no conflict of interest to declare for this article. 


\begin{abstract}
Falls represent a sizeable public health issue that has serious health-related consequences for both the individual and the medical system at large. Falls are one of the most common events that threaten the independence of older persons with one third of falls occurring in persons over the age of 65 and over $50 \%$ in persons over the age of 80 years (2). During an office appointment, senior adults are screened routinely for blood pressure, weight, medication adherence and lab result follow-up. One assessment that is commonly overlooked is evaluating seniors for fall risk.
\end{abstract}

The purpose of this study was to explore the use of the "Get Up and Go" test (GUGT) as a routine screening measure for community dwelling seniors. The research questions addressed were: 1) Is self-reported fall history related to GUGT scores in community dwelling seniors? 2) Is age related to the GUGT scores for a sample of community-dwelling seniors?; and 3) Is age related to self-reported fall history for a sample of community-dwelling seniors?

Recruitment of community-dwelling seniors occurred during a 3-month period at a primary care office setting in the urban San Francisco Bay area. A convenience sample of community-dwelling seniors $(\mathrm{N}=39)$ were recruited to participate in the study. All participants were age 65 or older, did not have a history of cognitive or neurological deficits, and were able to ambulate without the use of an assistive device such as a cane, walker or wheelchair. Participants reported fall occurrences for the last 12 months and performed the GUGT.

This study did not find statistical relevance between GUGT pass or fail status and fall history. Two groups of participants are of particular interest. Nine participants with a positive fall history were able to pass the GUGT and 8 seniors who reported no fall 
history failed the GUGT. Consistent with previous studies (12), one fall does not necessarily signify musculoskeletal or neurological deficits and is usually related to environmental hazards. Furthermore, previous studies have shown that a single fall report is a poor predictor of fall risk and that the number of reported falls by patients is not a reliable number due to the patient under-estimating or under-reporting fall occurrences. These findings suggest that fall history may not be a sensitive measure capable of identifying all at risk seniors. Thus if only fall history is used to identify risk, then some at risk community-dwelling seniors will not be identified while others may be identified by fall history but do not exhibit mobility deficits.

The relative ease in which the GUGT was performed, with minimum cost, strengthens the position that the GUGT should be performed as part of an annual examination for patients who are over the age of 65 . The GUGT results can then become the "sixth vital sign" for patients over the age of 65 with the initial GUGT result establishing baseline results for future patient fall risk evaluation. Given this evidence, it can be concluded that at the very least, both fall history and the GUGT test should be performed annually on community-dwelling seniors over the age of 65 . 


\section{INTRODUCTION}

During an office appointment, senior adults are screened routinely for blood pressure, weight, medication adherence and lab result follow-up. One assessment that is commonly overlooked is evaluating seniors for fall risk. Screening for fall risk can significantly impact the health of community-dwelling seniors (1). Falls represent a sizeable public health issue that has serious health-related consequences for both the individual and the medical system at large. Falls are one of the most common events that threaten the independence of older persons with one third of falls occurring in persons over the age of 65 and over $50 \%$ in persons over the age of 80 years old (2). According to Rubenstein and Josephson, $25-75 \%$ of seniors who have sustained a hip fracture due to a fall do not recover their pre-injury functional status (3). In the United States, falls are the leading cause of injury deaths among older adults (4). Additional complications from falls may include head trauma, soft tissue injuries, lacerations and fear of future falls with resultant decreased activity and isolation. Older adults are hospitalized for fall-related injuries five times more often than they are for any other injury (5). More than 1.8 million seniors were treated in emergency departments and 421,000 were hospitalized in 2005 (4). The cost of fall injuries for people age 65 or older in 2000 was $\$ 179$ million for fatal falls and $\$ 19$ million for nonfatal fall injuries (4).

\section{LITERATURE REVIEW}

The American Geriatrics Society website recommends that "all older persons who are under the care of a health professional (or their caregivers) should be asked at least once a year about falls" (6). Despite this guideline and overwhelming documented evidence to perform annual fall screening, only $34 \%$ of elderly patients receive any fall evaluation in the primary care setting (7). In comparison, seniors were more likely to 
receive appropriate care and screening for hypertension (77\%), heart failure (71\%), and diabetes mellitus $(57 \% ; 8)$. According to Wenger's study, only $37 \%$ of community dwelling seniors $(N=420)$ were routinely asked about fall occurrences when seen in the primary care setting (8).

In addition, patient reporting of fall occurrence has been shown to lack the sensitivity needed in order to be a true measure of fall risk in community-dwelling older adults (9). A recent study published by Mackenzie found that when seniors $(\mathrm{N}=264)$ were asked to keep a diary and self-report any fall occurrences, $13 \%$ of the participants gave false negative and $4 \%$ gave false positive reports. In 1990 , Hale and associates found that interviewing patients about their fall history and mobility were not "clinically useful predictors" of fall risk (9).

Falls often go unreported by the senior due to the fear of falling and decreasing confidence in the ability to remain independent (10). Fear of falling may result in the senior self-restricting activities, which may lead to increased social isolation and muscle atrophy which exacerbates fall risk (11). Furthermore, seniors may not identify incidents or behaviors that may signify a fall risk potential, such as near falls or decrease in lower extremity flexibility or strength.

A single fall occurrence has been found to be a weak indicator of fall risk, and is usually related to environmental hazards rather than neurological or musculoskeletal deficits (12). Multiple fall occurrences are more likely associated with underlying neurological or musculoskeletal deficits (12). Additionally, leg weakness was identified as the "most potent risk factor associated with falls", on average, increasing the risk of 
falls four fold (12). In addition, gait and balance disorders affect from $20 \%$ to $50 \%$ of seniors over the age of 65 and are associated with a three-fold increase risk for falls (3).

Primary care professionals can facilitate the identification of fall risk in seniors and play a significant role in fall prevention. Using a validated fall screening tool, such as the "Get Up and Go Test" (GUGT), may be a more sensitive measure of fall risk than the use of patient recall. The GUGT is a simple evaluation tool used to measure basic mobility that can easily be administered during a routine office exam in the primary care setting to evaluate community-dwelling older adults for fall risk.

In 1991, the GUGT was developed by Podsiadlo and Richardson and validated with 60 elderly patients from a geriatric day hospital (13). The test mimics the basic functional mobility required in everyday life by having the subject rise from a chair, ambulate three meters at their usual walking pace, turn around and sit back down in the original chair.

METHODS:

$D E S I G N$

The purpose of this study was to explore the use of the GUGT as a routine screening measure for community dwelling seniors. The research questions addressed were: 1) Is self-reported fall history related to GUGT scores in community dwelling seniors? 2) Is age related to the GUGT scores for a sample of community-dwelling seniors?; and 3) Is age related to self-reported fall history for a sample of communitydwelling seniors? The Institutional Review Board of San Jose State University provided the ethical review and approval for the study. 
SAMPLE

Recruitment of community-dwelling seniors occurred during a 3-month period at a primary care office setting in the urban San Francisco Bay area. A convenience sample of community-dwelling seniors $(\mathrm{N}=39)$ were recruited to participate in the study. All participants were age 65 or older, did not have history of cognitive or neurological deficits, and were able to ambulate without the use of an assistive device such as a cane, walker or wheelchair.

SETTING

Flyers posted at the clinic registration desk and in each of the six exam rooms provided information regarding the study. The physician or medical assistant personnel referred seniors, who expressed interest in participating in the study, to the primary researcher, who is a nurse practitioner intern. Participants were then escorted to the treatment room where the GUGT was performed. The GUGT equipment and course were measured and staged, according to the study protocol. Prior to the study implementation the GUGT equipment remained unaltered in the treatment room area during the entire 3month period of the study.

\section{PROCEDURES}

The GUGT is a widely used and simple measure of basic mobility in communitydwelling, older adults (13). In 1991, the GUGT was developed and validated by Podsiadlo and Richardson's study of 60 elderly patients from a geriatric day hospital (13). The test mimics the basic functional mobility required in everyday life. The test requires a subject to stand up from a sitting position, walk a distance of three meters (nine feet and 10 inches), turn around, walk back to the chair, and sit down. The subject performs the test twice, the first effort as a trial and the second effort as the timed test. 
Time taken to complete the timed test is strongly correlated to level of functional mobility. A timed result of greater than 12 seconds is suggestive of fall risk (14).

After receiving a thorough explanation of the GUGT, each participant was given the GUGT and asked to report fall history. The participants performed the test twice, ambulating at their preferred pace. The first performance was a timed trial and the second performance was the measured test. Each subject rose from a chair (with a seat height of $46 \mathrm{~cm}$ ) without using their arms, ambulated 3 meters, turned around and ambulated back to the chair, with completion of the test when the subject sat back down. As a safety precaution, the researcher stood to the side of each subject during the trial and test. Performance of the GUGT was timed with a standard stopwatch. Each participant received a fall risk educational packet obtained from the Centers from Disease Control National Center for Injury Control and Prevention.

RESULTS

Of the 39 participants, 28 were female (78\%) and 11 were male ( $22 \%)$.Ages ranged from 65 to 95 years old (mean age $=78.26, \mathrm{SD}=7.81$ ). Ethnicities represented included: Caucasian ( $n=32,82 \%)$, with Asian $(n=7,7 \%)$, Hispanic $(n=7,7 \%)$ and African American $(n=2,2 \%)$.

Mean scores (time in seconds) for the GUGT improved by approximately 1 second from the timed trial (Table 1). This difference was statistically significant $(t$-value $=-4.31, p$-value $=0.000)$. A Pearson's correlation revealed a strong relationship between the trial and test times $(r=0.900, p=0.000)$ establishing that the GUGT was a reliable indicator for this sample. 
As seen in Table 2, 17 (43\%) failed and $22(57 \%)$ passed the GUGT. Of the 17 who failed the GUGT, 9 reported a fall history and 8 did not. Of the 22 that passed the GUGT, 9 reported a fall history and $13(\%)$ did not. A chi-square test (Table 2) did not reveal a statistically significant relationship between the GUGT result (pass or fail) and self-reported fall history.

Looking at actual test scores rather than the results as pass or fail, the relationship between reported fall history and GUGT scores was re-examined. The mean GUGT score for those who reported falling was 11.35 seconds and the mean GUGT score for those who did not report falling was 11.26 seconds. The difference between these two means was not statistically significant $(t=-0.09, d f=36, p=0.929)$.

The data did show a strong correlation between GUGT scores and age $(r=0.322$, $p=0.045$ ) (see Table 3). As age increased, GUGT scores also increased (see Figure 1). For this sample, seniors with a positive fall history $(n=21)$ had a mean age of 78.72 years and the group of seniors with no fall history $(n=18)$ had a mean age of 77.86 years. These mean differences were not statistically significant $(t=-0.33, p=0.745)$. Fall history was not related to age $(d f=27, p=0.745)$.

\section{DISCUSSION}

This study did not find statistical relevance between GUGT pass or fail status and fall history. Two groups of participants are of particular interest. Nine participants with a positive fall history were able to pass the GUGT. Consistent with previous studies (12), one fall does not necessarily signify musculoskeletal or neurological deficits and is usually related to environmental hazards. Furthermore, previous studies have shown that 
a single fall report is a poor predictor of fall risk and that the number of reported falls by patients is not a reliable number due to the patient under-estimating or under-reporting fall occurrences.

Conversely, 8 seniors reported no fall history and failed the GUGT. This finding suggests that fall history may not be a sensitive measure capable of identifying all at-risk seniors. This finding suggests that if only fall history is used to identify risk, then some at risk community-dwelling seniors will not be identified. Furthermore, failing the GUGT suggests that the subject has decreased mobility, a more sensitive indicator of potential fall risk than self-reported positive fall history. This position is supported by Podsiadlo's study (1991) in which the GUGT was found to be a good measure of mobility (13).

\section{IMPLICATIONS FOR PRACTICE}

A strong correlation between GUGT scores and age was found. The relative ease in administering the GUGT, with minimum cost, and readily available equipment, strengthens the position that the GUGT should be performed as part of an annual examination for patients over the age of 65 .

Given this evidence, it can be concluded that at the very least, both fall history and the GUGT test should be performed annually on community-dwelling seniors over the age of 65 . Using the combination of fall risk history and GUGT test scores may provide the data the clinician needs to determine if seniors are at fall risk. Results may suggest whether the senior's fall risk is more likely related to extrinsic factors such as environmental hazards or intrinsic factors such as musculoskeletal or neurological deficits. 
The American Geriatrics Society's current recommendation of using the GUGT after a senior has reported a fall supports the use of the test as a trusted measure of functional performance. Implementing the GUGT only after a senior has reported a fall places more seniors at risk of injury than if the test were routinely performed as part of the annual examination process. As our population ages in place, there is an urgent need to improve fall risk identification and fall prevention strategies. The results of this preliminary study suggest that some seniors will not be identified as being at risk for falls under the current guidelines. Annual screening that includes both fall history and the GUGT test is a low risk, low cost measure that could contribute to the safety of our community-dwelling seniors.

The relative ease in which the GUGT was performed, with minimum cost, strengthens the position that the GUGT should be performed as part of an annual examination for patients who are over the age of 65 . The GUGT test results should become the "sixth vital sign" for patients over the age of 65 with the initial GUGT result establishing baseline for future patient fall risk evaluation. The initial GUGT baseline score will enable the clinician to detect deficits in functional mobility early, facilitating early fall prevention interventions. Given this evidence, it can be concluded that at the very least, both fall history and the GUGT test should be performed annually on community-dwelling seniors over the age of 65 .

\section{LIMITATIONS}

Several limitations of this study are acknowledged. The small size and relatively homogenous sample limits the ability to generalize the results to the entire population of community dwelling seniors. Additionally, data on the number of fall occurrences or the 
circumstances for each fall were not collected. This limits further exploration of the relationship between fall risk factors, such as such as environmental hazards or multiple fall occurrences, with fall history and GUGT scores. Future research is needed to determine if the GUGT can be used as the first initial measure of fall risk in community dwelling seniors. 
References

(1)Baker DK, King MB, Fortinsky RH., Graff LG, Gottschalk M., Acampora D et al. Dissemination of an evidence-based multicomponent fall risk assessment and management strategy throughout a geographic area. JAGS 2005 April; 53(4):675-680.

(2)Chou WC, Tinetti ME, King MB, Irwin K, Fortinsky RH. Perceptions of physicians on the barriers and facilitators to integrating fall risk evaluation and management into practice. J GEN INTERN MED 2006; 21: 117-122.

(3)Rubenstein LZ, Josephson KR. Falls and their prevention in elderly people: what does the evidence show? Med Clin N Am 2006. 90(5): 807-824.

(4)Centers for Disease Control and Prevention, National Center for Injury Control and Prevention [Online]. 2009, January 19 [cited May 8, 2009 May 8]; Available from: URL: http://www.cdc.gov/HomeandRecreationalSafety/Falls/adultfalls.html

(5)Alexander BH, Rivara FP, Wolf ME. The cost and frequency of hospitalization for fall-related injuries in older adults. Am J Public Health 1992 Jul 82(7):1020-1023.

(6)American Geriatrics Society Panel on Falls in Older Persons [Special Series: Clinical Practice]. JAGS 2001 49:664-672.

(7)Wenger NS, Solomon DH, Roth CP, MacLean CH, Saliba D, Kamberg CJ et al. The quality of medical care provided to vulnerable community-dwelling older patients. Ann Intern Med 2003 Nov 4;139(9):740-747.

(8) MacKenzie L, Myles J, D’Este C. Validation of self-reported fall events in intervention studies. Clin Rehabil 2006 Apr;20(4):331-339.

(9) Hale WA, Delaney MJ, McGaghie WC. Predicting elderly patients' mobility using fall history and physician assessment. Fam Med 1990 Sep-Oct;22(5):383-387.

(10) Fletcher PC, Hirdes JP. Restriction in activity associated with fear of falling among community-based seniors using home care services. Age Ageing. 2004 May;33(3):273279.

(11) Hawk C, Hyland JK, Rupert R, Colonvega M, Hall S. Assessment of balance and risk for falls in a sample of community-dwelling adults aged 65 and older. Chiropr Osteopat 2006 Jan 27;14 (3):1340-1348.

(12)Nevitt MC, Cummings SR, Kidd S, Black D. Risk factors for recurrent nonsyncopal falls: a prospective study. JAMA. 1989 May 12;261(18):2663-2668.

(13)Podsiadlo DR, Richardson S. The timed "up \& go": a test of basic functional mobility for frail elderly persons. J Am Geriatr Soc. 1991 Feb;39(2):142-148. 
(14) Bischoff HA, Stähelin HB, Monsch AU, Iversen MD, Weyh A, von Dechend M, et al. Identifying a cut-off point for normal mobility: a comparison of the timed "up and go" test in community-dwelling and institutionalized elderly women. Age Ageing 2003 May;32(3):315-320. 
Table 1

\begin{tabular}{|l|c|c|c|c|}
\hline & $\mathrm{N}$ & $\begin{array}{c}\text { Mean } \\
\text { (in seconds) }\end{array}$ & S.D. & S.E. Mean \\
\hline Test & 39 & 11.305 & 3.036 & 0.486 \\
\hline Trial & 39 & 12.580 & 4.026 & 0.645 \\
\hline Difference & 39 & -1.275 & 1.849 & 0.296 \\
\hline
\end{tabular}

$t$-value $=-4.31, p$-value $=0.000$

Table 2

GUGT as pass/fail, history of falls (yes/no answer) total (N=39)

\begin{tabular}{|c|c|c|c|}
\hline Fall History & $\begin{array}{c}\text { GUGT } \\
\text { Fail }\end{array}$ & $\begin{array}{c}\text { GUGT } \\
\text { Pass }\end{array}$ & Total \\
\hline YES & $\begin{array}{c}9 \\
(7.85)\end{array}$ & $\begin{array}{c}9 \\
(10.15)\end{array}$ & $\mathrm{n}=18$ \\
\cline { 2 - 4 } NO & $\begin{array}{c}8 \\
(9.15)\end{array}$ & $\begin{array}{c}13 \\
(11.85)\end{array}$ & $\mathrm{n}=21$ \\
& $\mathrm{n}=17$ & $\mathrm{n}=22$ & $\mathrm{~N}=39$ \\
\hline
\end{tabular}

Chi-Square $=0.559, d f=1, p=0.4555$ 
Figure 1

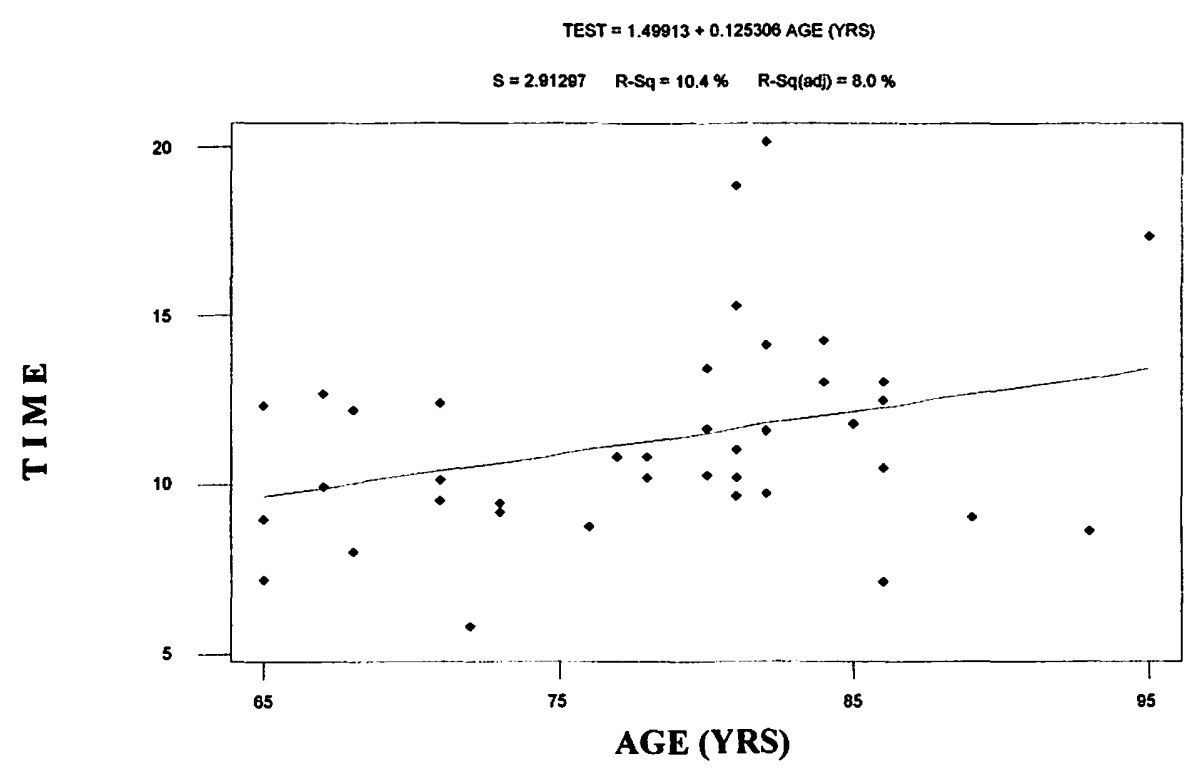

Table 3

\begin{tabular}{|c|c|c|c|c|}
\hline History Risk & $\mathrm{N}$ & Mean & Standard Dev. & SE Mean \\
\hline No, History of Falls & 21 & 77.86 & 5.98 & 1.3 \\
\hline Yes, History of Falls & 18 & 78.72 & 9.69 & 2.3 \\
\hline
\end{tabular}

$t$-value $=-0.33, p$-value $=0.745 d f=27$ 